\title{
The effect of a multicomponent exercise protocol (VIVIFRAIL@) on inflammatory profile and physical performance of older adults with different frailty status: study protocol for a randomized controlled trial
}

Marina Petrella ${ }^{1 \dagger}$, Ivan Aprahamian ${ }^{1,2^{*}+}$ (D), Ronei Luciano Mamoni ${ }^{1}$, Carla Fernanda de Vasconcellos Romanini ${ }^{1}$, Natália Almeida Lima', Everson de Cássio Robello ${ }^{1}$, Daniele Lima da Costa ${ }^{1}$, Vinicius Nakajima An ${ }^{1}$, Bianca Nobre Aguirre', Júlia Riccetto Galdeano', Isabela Cunha Fernandes', Salma S. Soleman Hernandez', Matteo Cesari ${ }^{3}$, John E. Morley ${ }^{4}$, Mikel Izquierdo ${ }^{5,6,7}$ and Richard C. Oude Voshaar ${ }^{2}$

\begin{abstract}
Background: To investigate whether an exercise intervention using the VIVIFRAIL@ protocol has benefits for inflammatory and functional parameters in different frailty status.

Methods/design: This is a randomized clinical trial in an outpatient geriatrics clinic including older adults $\geq 60$ years. For each frailty state (frail, pre-frail and robust), forty-four volunteers will be randomly allocated to the control group $(n=22)$ and the intervention group $(n=22)$ for 12 weeks. In the control group, participants will have meetings of health education while those in the intervention group will be part of a multicomponent exercise program (VIVIFRAIL $\odot$ ) performed five times a week (two times supervised and 3 times of home-based exercises). The primary outcome is a change in the inflammatory profile (a reduction in inflammatory interleukins [IL-6, TNF- a, IL1 beta, IL-17, IL-22, CXCL-8, and IL-27] or an increase in anti-inflammatory mediators [IL-10, IL1RA, IL-4]). Secondary outcomes are change in physical performance using the Short Physical Performance Battery, handgrip strength, fatigue, gait speed, dual-task gait speed, depressive symptoms, FRAIL-BR and SARC-F scores, and quality of life at the 12-week period of intervention and after 3 months of follow-up.

(Continued on next page)
\end{abstract}

\footnotetext{
* Correspondence: ivan.aprahamian@gmail.com

${ }^{+}$Marina Petrella and Ivan Aprahamian contributed equally to this work. ${ }^{1}$ Group of Investigation on Multimorbidity and Mental Health in Aging (GIMMA), Division of Geriatrics, Department of Internal Medicine, Faculty of Medicine of Jundiaí, 250 Francisco Telles st, Jundiaí 13202-550, Brazil

${ }^{2}$ Department of Psychiatry, University Medical Center Groningen, University of Groningen, Groningen, The Netherlands

Full list of author information is available at the end of the article
}

C The Author(s). 2021 Open Access This article is licensed under a Creative Commons Attribution 4.0 International License, which permits use, sharing, adaptation, distribution and reproduction in any medium or format, as long as you give appropriate credit to the original author(s) and the source, provide a link to the Creative Commons licence, and indicate if changes were made. The images or other third party material in this article are included in the article's Creative Commons licence, unless indicated otherwise in a credit line to the material. If material is not included in the article's Creative Commons licence and your intended use is not permitted by statutory regulation or exceeds the permitted use, you will need to obtain permission directly from the copyright holder. To view a copy of this licence, visit http://creativecommons.org/licenses/by/4.0/ The Creative Commons Public Domain Dedication waiver (http://creativecommons.org/publicdomain/zero/1.0/) applies to the data made available in this article, unless otherwise stated in a credit line to the data. 
(Continued from previous page)

Discussion: We expect a reduction in inflammatory interleukins or an increase in anti-inflammatory mediators in those who performed the VIVIFRAIL (c protocol. The results of the study will imply in a better knowledge about the effect of a low-cost intervention that could be easily replicated in outpatient care for the prevention and treatment of frailty, especially regarding the inflammatory and anti-inflammatory pathways involved in its pathophysiology.

Trial registration: Brazilian Registry of Clinical Trials (RBR-9n5jbw; 01/24/2020). Registred January 2020. http://www. ensaiosclinicos.gov.br/rg/RBR-9n5jbw/.

Keywords: Clinical trial, Elderly, Frailty, Inflammation, Physical exercise

\section{Background}

Frailty is a biological syndrome characterized by a reduction in physiological reserves and a decrease in resistance to stressors $[1,2]$. The worldwide prevalence of frailty is $4-16 \%$ over 65 years old and $25 \%$ in those aged 85 or older [3, 4]. Frailty is characterized as a main cause of death in seniors [5] and significantly increases the risk of falls, disability, hospitalizations and long-term care [6]. According to the theoretical model of the frailty phenotype, a multisystemic impairment of homeostasis trigger a cascade of dysregulation during the aging process, causing a cycle of energy reserve reduction [1, $2,7]$. Physical frailty is the biological model most used for diagnosis and is composed by three or more among five components (unintentional weight loss, self-reported fatigue, low handgrip strength, low physical activity; and low walking speed). Pre-frailty is identified by one or two of these components [2].

Chronic inflammation is a key element in its pathophysiology [7] and has its origin through factors that include aging changes, genetic and metabolic variations, environmental stressors, lifestyle, and chronic and acute diseases. Frail individuals have higher levels of inflammatory mediators, such as C-reactive protein (CRP), tumor necrosis factor alpha (TNF- $\alpha$ ) and interleukin-6 (IL-6) directly influencing frailty onset by degrading proteins, or indirectly, affecting the functioning of metabolic pathways $[8,9]$. Low-grade inflammation is associated with decreased strength and muscle mass, its intensity is inversely proportional to the practice of muscle strengthening activity and can be reduced with resistance training $[10,11]$.

Few controversial studies investigated the effect of exercise on inflammatory biomarkers in frailty. A stabilization of IL-6 and CRP was observed in frail and pre-frail older persons during physical training and nutritional support, while controls presented an increase in these cytokines [12]. Moreover, those who improved physical performance lowered IL-6 levels. In another study, a resistance training for knee flexors and extensors muscles did not influence low-grade inflammation in older adults. However, plasma levels of TNF type 1 receptors were inversely related to the muscle strength at the end of 12-weeks [13]. In youngers, the increase in the serum level of TNF- $\alpha$ after intervention correlated with reductions in muscle mass after a 4-week follow-up period, suggesting that TNF- $\alpha$ may play a role in muscle loss due to detraining [14]. Collectively, these studies show the potential anti-inflammatory role of physical activity.

Thus, this single-center parallel randomized controlled trial will allow to investigate whether a low-cost multicomponent exercise program called VIVIFRAILC [15, 16] has benefits for reducing inflammation and improve the functional status among older persons with different frailty status. This program is performed according to the functional capacity and has been demonstrated to be a safe and effective to reverse the functional decline associated with acute hospitalization in seniors [17, 18]. The specific objectives of this RCT will be evaluate the effectiveness of the VIVIFRAILC $[15,19]$ program with respect to the concentration of inflammatory and antiinflammatory mediators and in the functional status of older persons in the different frailty status during 12weeks. It is hypothesized that older persons submitted to the VIVIFRAIL@ exercise protocol will present a decrease in serum levels of pro-inflammatory interleukins, associated with an increase in serum levels of antiinflammatory interleukins and, secondarily, an improvement in the functional status is expected.

\section{Methods/design \\ Design and participants}

The present study is a single-center parallel randomized controlled trial comparing a multicomponent physical activity (i.e. VIVIFRAIL@) to usual health promotion. Participants are older adults from the Geriatrics Outpatient Center of Jundiaí Medical School, State of São Paulo, southwester of Brazil. These patients usually come from primary care centers or access the geriatric outpatient care directly.

Volunteers who meet the inclusion criteria will be randomly allocated to the intervention or control groups by an independent person, who is blind to their clinical data or frailty status. The data for participants in both groups will be obtained at three different times: at the 
beginning of the study, at the end of the study and after 3 months after the end of the intervention. The study flowchart is illustrated in Fig. 1. This study protocol follows the standard protocol for clinical trials in accordance with the SPIRIT2013 statement and follows the CONSORT statement for clinical trial transparency [20, 21]. The study is registered on the Brazilian Registry of Clinical Trials (REBEC) platform under the license RBR9n5jbw. The study was approved by the Research Ethics Committee of the Jundiaí Medical School. For any ancillary study that data collection/request is not covered in the original informed consent process for this main trial, another signed consent will be obtained from every participant.

\section{Recruitment and inclusion criteria}

The initial recruitment will be carried out with all older adults who followed up at the clinic during the year of 2019. The older adults that are receiving care at the clinic, that are aged 60 years or older, and who have signed the informed consent will be included in the study. The exclusion criteria will be: probable cognitive impairment identified using the 10-point cognitive screening instrument (10-CS) with a final score of 0 to 5

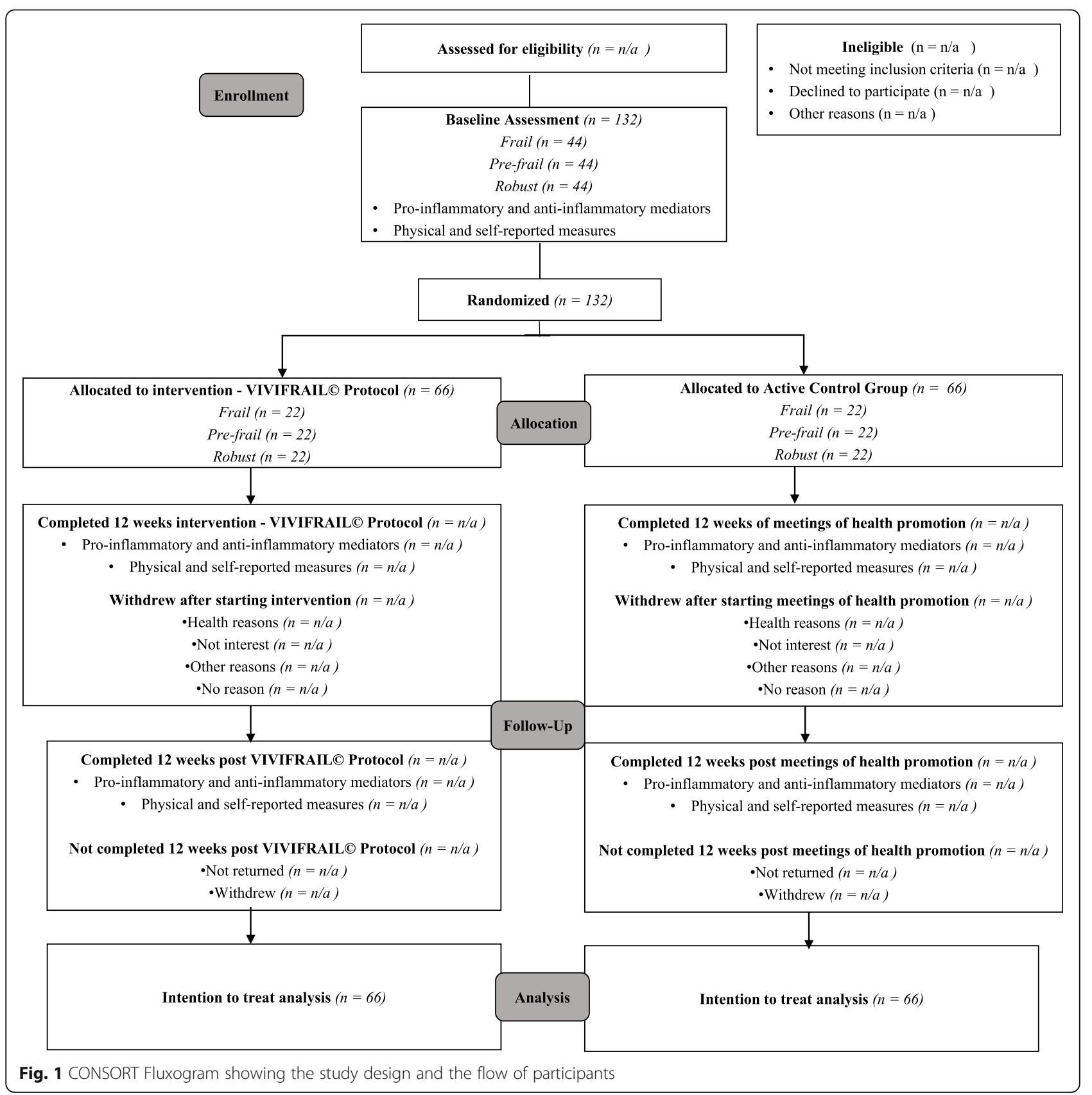


points; any contra-indication for the VIVIFRAIL@ [19] (Table 1), life-expectancy less than 12 months, permanent or temporary inability to walk; localized loss of strength and aphasia due to severe stroke; severe impairment of motor skills, speech or affectivity associated with Parkinson's disease in an advanced/unstable stage; severe hearing or vision deficits; cancer and autoimmune diseases in activity; cancer in the last 3 years; inability to perform the Short Physical Performance Battery (SPPB); limb amputation; and physical activity or physical therapy in the last 6 months.

Those who meet the inclusion criteria and agree with the study criteria presented by the researcher carrying out the recruitment (a medical doctor or physical therapist) will sign the consent information term and will be submitted to the assessment of the Frailty Physical Phenotype criteria proposed by Fried and colleagues (2001), according to the description below:

- Fatigue: it will be evaluated through self-report using questions 7 and 20 of the Center for Epidemiological Studies - Depression (CES-D) scale. The volunteers will be asked about the frequency in which they perceived to make an effort to perform usual tasks and the frequency with which they were unable to carry out their activities in the last week. Positive affirmation "most of the time" or "always" in any of the two questions will be considered a manifestation of fatigue.

- Unintentional weight loss in the last year: older person with unintentional weight loss greater than $5 \%$ of body weight will be scored according to this criterion, adjusted for sex and body mass index (BMI).

- Hand grip strength will be performed using a manual hydraulic dynamometer (Jamar hand dynamometer, model J00105, Lafayette Instrument Company, Lafayette, Lousiania, USA). This instrument is composed of a

Table 1 Absolute and relative contraindications for physical activity according to VIVIFRAILOProtocol

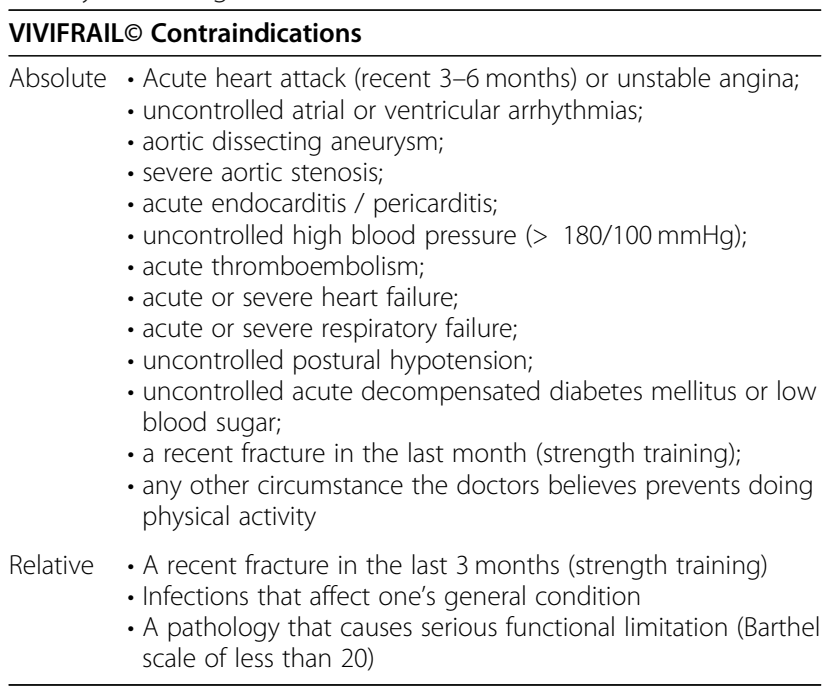

closed hydraulic system that measures the amount of force produced by an isometric contraction applied over its loops, and the hand grip is recorded in kilogramforce. It will be performed with the individual sitting in a chair without armrests and with their feet resting on the floor, with adducted shoulder, the elbow flexed at $90^{\circ}$, the forearm in neutral position and the wrist between 0 and $30^{\circ}$ in extension. Prior to the evaluation, the volunteer will be familiarized with the instrument for the opportunity to handle the dynamometer before recording the measurements and will be guided on the evaluation procedure. The volunteer will be instructed to tighten the dynamometer handle tightly held by the volunteer's dominant hand and verbal commands will be provided to encourage volunteers to produce maximum grip strength. Three evaluations will be carried out, with a one-minute rest between each one and the average of the repetitions, in kilogram-force (kgf), will be used for statistical analysis. Low grip strength will be indicated by the average values interpreted according to sex and BMI. For females, will be considered low handgrip strength values $\leq 17 \mathrm{~kg}$ for those with $\mathrm{BMI} \leq 23 \mathrm{~kg} / \mathrm{m}^{2}$, values $\leq 17.3 \mathrm{~kg}$ for a BMI between $23.1-26 \mathrm{~kg} / \mathrm{m}^{2}$, values $\leq 18$ $\mathrm{kg}$ for a BMI between $26.1-29 \mathrm{~kg} / \mathrm{m}^{2}$ and values $\leq 21 \mathrm{~kg}$ for females with BMI $>29$. For males, will be considered a low hand grip strength values $\leq 29 \mathrm{~kg}$ for those with $\mathrm{BMI} \leq 24 \mathrm{~kg} / \mathrm{m}^{2}$, values $\leq 30 \mathrm{~kg}$ for a BMI between 24 , $1-26 \mathrm{~kg} / \mathrm{m}^{2}$, values $\leq 30 \mathrm{~kg}$ for a BMI between $26.1-28$ $\mathrm{kg} / \mathrm{m}^{2}$ and values $\leq 32 \mathrm{~kg}$ for males with BMI $>28$.

- Low gait speed: it will be assessed when asking the older person to walk at their usual speed for $4.6 \mathrm{~m}$, repeating the route 3 consecutive times. The average speed obtained in each of the routes will be interpreted according to the height and gender of the participants. Will be considered with low gait speed the male participants with a height $\leq 173 \mathrm{~cm}$ who took a time $\geq 7 \mathrm{~s}$ or those with height $>173 \mathrm{~cm}$ who took a time $\geq 6 \mathrm{~s}$. For females' participants, will be considered with low gait speed those higher than $159 \mathrm{~cm}$ who took $\geq 7 \mathrm{~s}$ or those higher than $159 \mathrm{~cm}$ who took a time $\geq 6 \mathrm{~s}$ to complete the test.

- Low level of physical activity: Low physical activity is defined as spending less than $383 \mathrm{cal}$ per day for males and $270 \mathrm{cal}$ for females, corresponding to the lowest quintile of energy expenditure in the older population. The energy expenditure will be measured with some items of the Minnesota Leisure Activity Questionnaire, which has been translated and validated in Portuguese [22]. Based on self-report frequency and duration of physical activities (including sports and leisure activities), the calculation of caloric expenditure will be performed by multiplying the metabolic equivalent of the task (MET) of each activity by the body weight $(\mathrm{Kg})$, time (minute) and the predetermined measure of 0.0175 . 
After evaluating the Frailty Physical Phenotype criteria, participants who have $1-2$ of these components will be considered as pre-frail, 3 or more components as frail, and those without any as robust.

\section{Randomization and blinding}

Participants will be allocated to groups (intervention or control group) randomly in 1:1 rate. The randomization sequence will be generated by an independent professional using an online system (www.randomization.com) to allocate 22 participants from each frailty group (i.e. frail, pre-frail and robust) to the control group $(n=66)$ and in the intervention group $(n=66)$. The type of intervention that the participant will undergo during the study will be indicated on a sheet of paper inserted in opaque, sequentially numbered, sealed envelopes. These envelopes will be prepared by a researcher who is not involved in enrolling the participants, in assigning them to their groups or performing follow-up measurements and will be delivered after baseline measurement. Follow-up measurement at the end of intervention period and after 3 months will be performed by a researcher who will be unaware of group allocation.

The professionals responsible for the physical and blood assessments will be blind to participant's group. It will not be possible to blind the allocation of groups from the professional responsible for the intervention since the VIVIFRAIL protocol change according to patients' profile. It will not be possible to hide the intervention of the participants, who will know about the allocation in different groups at random. However, they will not be aware of which group they were allocated. Raters and data-analysts will keep blinded in relation to the intervention performed by the volunteer.

\section{Measurements}

Outcome measures will be done at three moments: baseline, after 12 weeks (end of intervention), and 24 weeks.

\section{Inflammation}

The peripheral blood of all participants will be collected. From everyone, approximately $9 \mathrm{~mL}$ of blood will be collected in tubes containing clot activator and $9 \mathrm{~mL}$ in tubes containing sodium heparin for peripheral blood mononuclear cells (PBMCs) and polymorphonuclear cells (PMNs) isolation. The serum will be separated after clot formation by centrifugation at $1200 \mathrm{~g}$ for $15 \mathrm{~min}$ at room temperature, then the serum will be collected, aliquoted and immediately stored at $20^{\circ} \mathrm{C}$. The cytokine measurement will be performed using ELISA with specific commercial kits for IL-6, TNF- $\alpha$, IL1beta, IL-17, IL-22, CXCL-8, IL1RA, and IL-27 (R\&D Systems and Biolegend manufacturers' instructions).
PBMCs will be isolated using Ficoll-Hypaque density gradient centrifugation (density 1.077 - Pharmacia Biotech, Piscataway, NJ, USA). After removing PBMCs, the buff-coat cells (containing PMNs) will be collected and diluted in fresh RPMI medium and submitted to new centrifugation over a Ficoll-Hypaque solution at a density of 1.119). After separation, PBMCs and PMNs will be resuspended $\left(2 \times 10^{6}\right.$ cells $\left./ \mathrm{mL}\right)$ in RPMI medium supplemented with fetal bovine serum (10\%), L-glutamine, sodium pyruvate and gentamicin (RPMI-S) and distributed in 24-well plates. Cultures will be maintained without additional stimulation or stimulated with ultrapure LPS (100 ng/mL - Invivogen) and PMA (100 ng/mL - Sigma) for PMNs and with ultrapure LPS $(100 \mathrm{ng} / \mathrm{mL}$ - Invivogen) and PHA $(10 \mathrm{mg} / \mathrm{mL})$ for PBMCs. The cells will be kept for $24 \mathrm{~h}$, at $37^{\circ} \mathrm{C}$ in a $\mathrm{CO}_{2}$ incubator (5\%). After the culture period, the supernatant will be collected and stored at $-80^{\circ} \mathrm{C}$ and will be evaluated by ELISA with commercial kits for each cytokine (IL-10, IL-4, IFNgamma, IL-17, TNF- $\alpha$, IL-6) (R\&D Systems and Biolegend).

The details of the pro-inflammatory and antiinflammatory mediators investigated in this study are presented in the Table 2.

\section{Physical performance}

The SPPB battery allows the evaluation of the performance of the lower limbs. It is composed of the assessment of standing balance, gait speed and muscle strength. The SPPB varies between 0 and 12 points, with higher score representing better performance. It is a valid instrument for screening for frailty and predicts disability, institutionalization and death, so that a change of 1 point represents a relevant issue [23, 24].

\section{Secondary measures}

The gait evaluation during the simultaneous performance of a cognitive task is a useful tool for functional evaluation in frail older patients, allowing to predict falls [25]. The participants will perform a $6 \mathrm{~m}$ gait velocity test $(6 \mathrm{~m}-\mathrm{GVT})$ while naming animals aloud. The cognitive score during the dual task will be measured by counting the number of animals named. Depression symptoms will be evaluated throughout the Geriatric Depressive Scale (GDS) [26], composed by 15 items in which mental health related questions are asked in reference to how the participants felt over the past week. The quality of life will be evaluated though the EQ-5D questionnaire ("EuroQol - a new facility for the measurement of health-related quality of life," 1990). The questionnaire its composed by five dimensions (mobility, selfcare, usual activities, pain/discomfort and anxiety/depression with 3 levels (no problems, some problems, and 
Table 2 Pro-inflammatory and anti-inflammatory mediators

\begin{tabular}{|c|c|c|}
\hline Mediator & Major Cellular Sources & Major Activities \\
\hline $\begin{array}{l}\text { IFN- } \\
\text { gamma }\end{array}$ & Th1 cells, NK cells & $\begin{array}{l}\text { Activation of inflammatory macrophages (M1), inhibition of Th2 responses, induction of leukocyte } \\
\text { migration. }\end{array}$ \\
\hline IL-1beta & $\begin{array}{l}\text { Monocyte/macrophages, } \\
\text { PMNs. }\end{array}$ & Synthesis of acute-phase proteins by hepatocytes, induction of local and systemic inflammatory effects. \\
\hline IL-1RA & $\begin{array}{l}\text { Monocyte/macrophages, } \\
\text { dendritic cells. }\end{array}$ & Specific inhibitor of IL-1alpha and IL-1 beta by competition with the cellular receptor. \\
\hline IL-4 & Th2 cells, mast cells, B cells & $\begin{array}{l}\text { Induction of Th2 lymphocyte development, inhibition of pro-inflammatory and Th1 cytokine production, } \\
\text { activation of anti-inflammatory macrophages (M2). }\end{array}$ \\
\hline IL-6 & $\begin{array}{l}\text { Monocyte/macrophages, T } \\
\text { cells, PMNs. }\end{array}$ & $\begin{array}{l}\text { Produced during the inflammatory response, induces the synthesis of acute-phase proteins by hepatocytes } \\
\text { but presents an inhibitory effect on TNF- } a \text { and IL-1 production by macrophages. }\end{array}$ \\
\hline $\begin{array}{l}\text { IL-8 } \\
\text { (CXCL8) }\end{array}$ & $\begin{array}{l}\text { Monocytes/macrophages, } \\
\text { PMNs. }\end{array}$ & Major chemotactic cytokine (chemokine) for neutrophils. \\
\hline IL-10 & $\begin{array}{l}\text { Monocyte/macrophage, Th2 } \\
\text { cells, B cells }\end{array}$ & $\begin{array}{l}\text { Inhibition of pro-inflammatory cytokine production by macrophages and neutrophils, inhibition of Th1 } \\
\text { cytokine production. }\end{array}$ \\
\hline IL-17 & Th17 cells & Activation of neutrophils, induction of extracellular matrix remodeling. \\
\hline IL-22 & Th17 and Th22 cells & $\begin{array}{l}\text { Induction of epithelial cell proliferation and production of antimicrobial peptides by epithelial cells and } \\
\text { neutrophils. }\end{array}$ \\
\hline IL-27 & Macrophages, dendritic cells. & Antagonist of Th1, Th2 and Th17 inflammatory responses, induction of Tr1 (regulatory) cells. \\
\hline TNF- $a$ & $\begin{array}{l}\text { Monocyte/macrophages, } \\
\text { PMNs, T cells. }\end{array}$ & $\begin{array}{l}\text { Synthesis of acute-phase proteins by hepatocytes, recruitment, and activation of cells into inflammatory } \\
\text { sites, induction of insulin resistance. }\end{array}$ \\
\hline
\end{tabular}

extreme problems). All participants also will be assessed with FRAIL-BR [1] and SARC-F [27, 28].

To register the physical activity frequency after the intervention period, a diary will be used and the times per week of physical activity performed by the participants will be computed.

\section{Interventions}

\section{Control group}

To ensure that possible changes in the serum levels of biomarkers were not related to frailty, participants allocated to control group will participate in monthly meetings of health promotion. To minimize bias effect of socialization on the perception of health, the meetings will include lectures on topics related to health, such as food, use of medicines, prevention and health promotion and socialization activities [29]. Participants will be guided to continue the usual primary and secondary health care (public or private) and community activities. Telephone contact will be made after absences from meetings.

\section{Intervention group}

The VIVIFRAILC $[15,19]$ multicomponent exercise intervention protocol was developed in Europe (Erasmus+ programme, European Union) and consists of resistance training, gait retraining, and balance training. Different functional capacity levels will be determined based on the scores obtained from the SPPB and the 6-m gait velocity test, with each leading to the recommendation of a certain customized multicomponent physical exercise program (Program A, B, C1, C2 or D). These programs are composed by arm and leg strength and power exercises, balance and coordination to prevent falls, flexibility and cardiovascular endurance exercises $[15,19]$.

After the initial assessment and categorization of the volunteer in any of the physical exercise programs, a multicomponent program will be carried out for 12 weeks, totaling 60 sessions. Two weekly supervision sessions will be held, lasting $60 \mathrm{~min}$ each, with an interval of 1 day between them. Participants will receive the materials (elastic bands, towel and bottles with water/sandy) to perform the exercises and will be trained to perform exercises individually at home with a frequency of 3 days a week, in order to complete 5 days of activity per week. Instructions will be properly adapted to the focused population and will be provided to the volunteers in the Portuguese language.

The VIVIFRAILC program is composed by arm and leg strength and power exercises, balance and coordination to prevent falls, flexibility and cardiovascular endurance (i.e walking) exercises $[16,30]$. The proposed exercises' sets and repetitions, intensity of progression of each Program are shown in Table 3 and illustrated in Fig. 2.

The intervention will be discontinued due to any condition or adverse event that does not allow the performance of exercises with security or if requested by any participant. If necessary, one medical team will be disposable to offer assistance at any moment.

The participants will be instructed to does not enroll in other physical activity intervention during the period of 12 weeks of intervention.

After initial assessment and categorization, the multicomponent program will be carried out for 12 weeks, 
Table 3 Proposed exercises sets, repetitions (Reps) and intensity (Intst) of progression of each program of the VIVIFRAIL@ multicomponent exercise methodology

\begin{tabular}{|c|c|c|c|c|c|c|}
\hline & & Program A & Program B & & $\begin{array}{l}\text { Program C } 1 \\
\text { and C2 }\end{array}$ & Program D \\
\hline \multirow[t]{2}{*}{$\begin{array}{l}\text { Resistance } \\
\text { training }\end{array}$} & $\begin{array}{l}\text { Sets / } \\
\text { Reps }\end{array}$ & $\begin{array}{l}\text { Week 1-2: } 2 \text { sets / } 10 \text { reps } \\
\text { Week 3-4: } 2 \text { sets / } 10 \text { reps } \\
\text { Week 5-6: } 2 \text { sets / } 10 \text { reps } \\
\text { Week 7-8 } 2 \text { sets / } 10 \text { reps } \\
\text { Week 9-10: } 2 \text { sets / } 10 \text { reps } \\
\text { Week 11-12: } 2 \text { sets / } 10 \text { reps }\end{array}$ & \multicolumn{4}{|l|}{$\begin{array}{l}\text { Week 1-2: } 2 \text { sets / } 10 \text { reps } \\
\text { Week 3-4: } 2 \text { sets / } 12-15 \text { reps } \\
\text { Week 5-6: } 3 \text { sets / } 12 \text { reps } \\
\text { Week 7-8 } 2 \text { sets / } 10 \text { reps } \\
\text { Week 9-10: } 2 \text { sets / 12-15 reps } \\
\text { Week 11-12: } 3 \text { sets / 12-15 reps }\end{array}$} \\
\hline & Intst & \multicolumn{5}{|c|}{$\begin{array}{l}\text { Determine the weight that allows to do the exercise properly without stopping yet makes feel as though they have made } \\
\text { an effort by the end: } \\
\text { Week 1-6: } 30 \text { times } \\
\text { Week 6-12: } 20 \text { times }\end{array}$} \\
\hline \multirow[t]{4}{*}{$\begin{array}{l}\text { Cardiovascular } \\
\text { training }\end{array}$} & \multirow[t]{3}{*}{$\begin{array}{l}\text { Sets / } \\
\text { Reps }\end{array}$} & \multirow{3}{*}{$\begin{array}{l}\text { Time walking / rest / times } \\
\text { Week 1-4: 5-10s / 10s / 5-7 } \\
\text { Week 5-6: 10-15 s / 20s / 5-7 } \\
\text { Week 7-8: } 15-30 \text { s / } 20 \text { s / 5-10 } \\
\text { Week 9-10: 30-45 s / 20s / 5-10 } \\
\text { Week 11-12: 45-60s / 20s/12-15 }\end{array}$} & \multirow{3}{*}{$\begin{array}{l}\text { Time walking / rest / times } \\
\text { Week 1-4: 20s / 10s / 5-7 } \\
\text { Week 5-6: 20-25 s / 20s / 5-7 } \\
\text { Week 7-8: 25-35 s /20s / } 5 \\
\text { Week 9-10: 45 s / 20s / } 5 \\
\text { Week 11-12: 50-70s /20s/12-15 }\end{array}$} & $\begin{array}{l}\text { Time } \\
\text { time }\end{array}$ & $\begin{array}{l}\text { e walking / rest / } \\
\text { es }\end{array}$ & \multirow{3}{*}{$\begin{array}{l}\text { Time walking / rest / } \\
\text { times } \\
\text { Week 1-2: } 15 \text { min / } \\
\text { 30s / } 2 \\
\text { Week 3-4: } 15 \text { min / } \\
\text { 30s / 3 } \\
\text { Week 5-6: } 20 \text { min / } \\
\text { 30s / 2 + } 15 \text { min } \\
\text { Week 7-8: 30-35 min } \\
\text { /30s / 2 } \\
\text { Week 9-10: 50-70 } \\
\text { min } \\
\text { Week 11-12: 50-70 } \\
\text { min }\end{array}$} \\
\hline & & & & & $\begin{array}{l}\text { Week 1-2: 3-5 } \\
\text { min / 30s / } 2 \\
\text { Week 3-4: } 5 \text { min } \\
\text { / 30s / 2 } \\
\text { Week 5-6: } 5 \text { min } \\
\text { / 30s / } 3 \\
\text { Week 7-8: 5-7 } \\
\text { min /30s / } 3 \\
\text { Week 9-10: 7- } \\
12 \text { min } \\
\text { Week 11-12: } \\
\text { 12-20 min }\end{array}$ & \\
\hline & & & & \multirow{2}{*}{\multicolumn{2}{|c|}{ 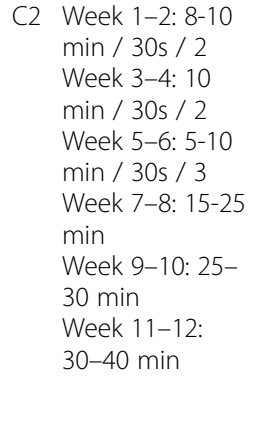 }} & \\
\hline & Intst & Usual walking pace & & & & \\
\hline $\begin{array}{l}\text { Balance } \\
\text { training }\end{array}$ & $\begin{array}{l}\text { Sets / } \\
\text { Reps }\end{array}$ & $\begin{array}{l}\text { Remain in the same position, and do } \\
\text { 2-3 times with each leg, counting to: } \\
\text { Week 1-2: 5-10 } \\
\text { Week 3-4: } 10 \\
\text { Week 5-6: } 15 \\
\text { Week 7-8: } 20 \\
\text { Week 9-10: } 25 \\
\text { Week 11-12: } 30\end{array}$ & $\begin{array}{l}\text { Remain in the same position and do } \\
\text { 2-3 times with each leg, counting to: } \\
\text { Week 1-2: } 10 \\
\text { Week 3-4: } 15 \\
\text { Week 5-6: } 20 \\
\text { Week 7-12: } 30 \text { + Walk } 10 \text { steps/ } \\
2 \text { times + Walk in a relaxed way } \\
\text { and step over } 5 \text { obstacles / } 8 \text { times }\end{array}$ & \multicolumn{3}{|c|}{$\begin{array}{l}\text { Remain in the same position } \\
\text { counting to: } \\
\text { Week 1-2: } 10 \\
\text { Week 3-4: } 15 \\
\text { Week 5-6: } 20 \\
\text { Week 7-12: } 30 \\
\text { These exercises will be done } \\
2 \text { times with each leg, followed by: } \\
\text { Walk } 10 \text { steps/ } 2 \text { times + Walk in } \\
\text { a relaxed way and step over } \\
5 \text { obstacles / } 8 \text { times }\end{array}$} \\
\hline \multirow[t]{3}{*}{ Flexibility } & Intst & \multicolumn{5}{|l|}{$\begin{array}{l}\text {-Change the position of the arms; } \\
\text {-Cross your arms } \\
\text { - Use of different surfaces } \\
\text { - Eyes closed. }\end{array}$} \\
\hline & $\begin{array}{l}\text { Sets / } \\
\text { Reps }\end{array}$ & \multicolumn{5}{|l|}{$\begin{array}{l}\text { Week 1-6: } 2 \text { sets of } 3 \text { reps } \\
\text { Week 7-12: } 3 \text { sets of } 3 \text { reps }\end{array}$} \\
\hline & Intst & \multicolumn{5}{|l|}{$\begin{array}{l}\text { Remain in the same position } \\
\text { for } 10-12 \mathrm{~s}\end{array}$} \\
\hline
\end{tabular}






totaling 60 sessions. Two weekly supervisioned sessions will be held $(60 \mathrm{~min})$ with an interval of 1 day between them. Participants will receive all materials (elastic bands, towel and bottles with water/sand) to perform the exercises and will be trained to perform exercises individually at home 3 days weekly in order to complete 5 days per week. Instructions will be adapted to the focused population and will be provided in Portuguese. Adherence to the intervention will be monitored using a frequency control spreadsheet before the start of each session. Participants will be instructed to report possible adverse events.

Participants may withdraw from the study for any reason at any time. The investigator also may withdraw participants from the study in order to protect their safety and/or if they are unwilling or unable to comply with required study procedures. To promote participant retention and complete follow-up, all the participants will receive written feedback regarding the assessments performed.

\section{Outcomes}

Primary and secondary outcomes will be accessed at baseline, after 12 weeks (end of intervention) and 24 weeks (Table 4).

\section{Primary outcomes}

The primary outcome measure is a change in the inflammatory profile after a 12-week multicomponent physical exercise program (VIVIFRAIL $\odot$ ), whether a reduction in inflammatory mediators in serum (IL-6, TNF- $\alpha$, IL1beta, IL-17, IL-22, and CXCL-8) or culture supernatants (IL-6, TNF- $\alpha$, IFN-gamma and IL-17) or an increased production of anti-inflammatory mediators (IL1RA and, IL-27) in serum or IL-10 and IL-4 in culture supernatants. We hypothesize that the intervention would lead to an anti-inflammatory profile.

\section{Secondary outcomes}

Secondary outcomes are a change in: (1) physical performance according to the SPPB, (2) handgrip strength, (3) fatigue according to specific items of the CES-D scale, (4) gait speed, (5) dual-task gait speed, (6) depressive symptoms, (8) FRAIL and SARC-F scores, and (7) quality of life.

We hypothesize that the intervention group could present at least a 1-point increase in the SPPB, better measurements of strength and gait speed, less referred fatigue and depressive symptoms, and better quality of life. 
Table 4 Primary and secondary outcomes for the participants of the study

\begin{tabular}{|c|c|c|c|c|}
\hline & Measurement & $\begin{array}{l}\text { Baseline } \\
\text { (T0) }\end{array}$ & $\begin{array}{l}\text { Post } 12 \text { week of Intervention } \\
\text { (T1) }\end{array}$ & $\begin{array}{l}12 \text { weeks of follow-up } \\
\text { (T2) }\end{array}$ \\
\hline \multirow[t]{2}{*}{ Primary outcomes } & Plasma levels of inflammatory cytokines & $x$ & $x$ & $x$ \\
\hline & Function of leukocytes in the peripheral circulation & $x$ & $x$ & $x$ \\
\hline \multirow[t]{10}{*}{ Secondary outcomes } & Short Physical Performance Battery & $x$ & $x$ & $x$ \\
\hline & Maximal isometric handgrip strength (kg.f) & $x$ & $x$ & $x$ \\
\hline & Gait speed (m/s) & $x$ & $x$ & $x$ \\
\hline & Fatigue & $x$ & $x$ & $x$ \\
\hline & Geriatric depression Scale (GDS) & $x$ & $x$ & $x$ \\
\hline & Dual-task ${ }_{\text {gait }}$ verbal $(\mathrm{m} / \mathrm{s})$ & $x$ & $x$ & $x$ \\
\hline & Quality of Life (EQ-5D) & $x$ & $x$ & $x$ \\
\hline & FRAIL-BR & $x$ & $x$ & $x$ \\
\hline & SARC-F & $x$ & $x$ & $x$ \\
\hline & Physical activity frequency during follow-up & & & $x$ \\
\hline
\end{tabular}

All the participants will be coded using numbers and the data will be stored electronically. After storage, data will be checked by a second researcher to ensure data quality. All participant information will be stored in areas with limited access. All records that contain names or other personal identifiers will be stored separately from study records identified by code number.

\section{Statistical analyses}

First, sample calculation was based in a previously published results from a clinical trial of resistive physical intervention among frail older adults [31]. This study is similar to our design and outcomes. In this trial, outcomes involved inflammatory biomarkers. To date, VIVI FRAIL trials were done in inpatients and nursing home patients and without inflammatory biomarkers as outcome measurement. For a 30\% reduction in IL-6 with $80 \%$ power and a $5 \%$ error, we would have 18 older adults in each group for 12 weeks. Assuming a drop out until $25 \%$ within this period, the groups should be composed of 22 elder adults each.

Statistical analyzes will be performed using the SPSS program (version 23.0; SPSS, Inc., USA) and $\mathrm{R}$ version 3.6.2. Initially, the Shapiro Wilk and Levene tests will be used to test the distribution and homogeneity of the data. Descriptive analysis will be performed and the means and standard deviation of the variables with normal distribution will be presented, and the median and maximum and minimum values for the non-normal variables and $95 \%$ confidence intervals.

Analysis by intention to treat will be performed. A sensitivity analysis will be performed for missing data, through multiple imputation. To compare the variables between the groups, the Student t-test will be used or the Mann-Whitney test for non-parametric variables. To assess the difference between the moments of intervention, one-way analysis of variance (ANOVAoneway) with repeated measures or the Friedman test for nonparametric variables will be used.

\section{Discussion}

Immune dysregulation is underlying frailty, interacting with neuroendocrine dysregulation and neuromuscular dysfunction. Considered a marker of aging, chronic lowgrade inflammation is associated with common diseases in aging, with adverse outcomes such as death and the functional impairment $[2,6,32]$, in addition to being a possible pathophysiological mechanism of frailty (Gale, Baylis, Cooper, \& Sayer, 2013). As it is a dynamic condition, an older person can move between the different stages of frailty status [29]. Therefore, investigating whether conservative interventions used for the prevention and treatment of frailty influence low-grade chronic inflammation in frail and pre-frail older persons will help to understand the physiological mechanisms of frailty.

In addition to improving essential aspects for maintaining the health and functionality of older persons (eg, increasing muscle strength), improving balance and preventing falls, physical exercise has been shown to decrease the levels of inflammatory biomarkers [33]. In a recent systematic review, the combination of muscle strengthening, and protein supplementation proved to be an effective and feasible intervention to reverse or prevent frailty [34]. However, the quality of the studies still leaves doubts about this evidence.

Since the balance between inflammatory and antiinflammatory biomarkers has been suggested as a determinant for the severity of conditions associated with aging [35], understanding the effect of exercise on the inflammatory profile of frail and pre-frail older persons will contribute to a better understanding of perspectives for the prevention and treatment of frailty and will 
represent an advance in the knowledge about the use of biomarkers for monitoring frailty.

This is the first study to perform the VIVIFRAILC methodology in a sample of frail and pre-frail outpatient older adults from a middle-income country in order to verify its effect on the inflammatory profile and physical functional parameters. The VIVIFRAIL $\odot$ exercise protocol is a low-cost intervention that could be easily replicated in the community (Basic Health Units, Community Centers, etc.) $[15,19]$. If our results confirm our hypothesis, this study could contribute with an easy to implement methodology to be disseminated acting at the person end public health level after further multicenter trials with a higher number of participants.

In the next future this project offers the opportunity to test and disseminate "in the real life" a novel prescription exercise tool (VIVIFRAIL $\odot) ~[16,30]$ with regard to the modification of low-grade chronic inflammation and in physical functional parameters of frail and pre-frail older outpatients. It will yield direct information about the effects of a specific and individualized designed exercise program in those geriatric conditions. In the long run, such results will contribute to the better understanding of physiopathological mechanisms of physical exercise in the treatment of frailty. It is also expected that the results of the present study will assist in advancing the use of inflammatory biomarkers and physical functional measures to monitor chronic low-grade inflammation in frail and pre-frail older persons included in programs of prevention and rehabilitation of frailty. Another important expected result in our project is to stimulate the prescription of exercise in this population in order to prevent disability. Finally, with the actual target of a novel era of precision medicine, our results could be a significant step forward to a "precise prescription of exercise recipe" for older patients with frailty. Important questions remain about safety, effectiveness, and the inherent variability between people in response to exercise [36, 37].

\section{Abbreviations}

10-CS: 10-point cognitive screening instrument; $6 \mathrm{~m}$-GVT: $6 \mathrm{~m}$ gait velocity test; BMI: Body mass index; CES-D: Center for Epidemiological Studies Depression; CRP: C-reactive protein; GDS: Geriatric Depressive Scale; IL: Interleukin; Kgf: Kilogram-force; MET: Metabolic equivalent of the task; PBMCs: Peripheral blood mononuclear cells; PMNs: Polymorphonuclear cells; REBEC: Brazilian Registry of Clinical Trials; SPPB: Short Physical Performance Battery; TNF-a: Tumor necrosis factor alpha

\section{Acknowledgments}

Not Applicable.

\section{Authors' contributions}

The protocol was developed by MP, IA, RLM, RCOV, MI. MC and JEM contributed to study conception and design, and project planning. IA, MP, CFVR, NAL, DLC, NBA, JRG, VNA, BA, ICF, SSSH, e ECR are in charge with study protocol implementation. RCOV provided advice on the statistical analysis and writing. MP, IA, RLM, MI and RCOV prepared the initial manuscript. All authors reviewed the final manuscript prior to submission. All authors read and approved the final manuscript.

\section{Funding}

Grant number 2019/27618-0 São Paulo Research Foundation (FAPESP) for laboratorial analyses. The agency did not interfere in the writing of this manuscript nor in the conduction of this clinical trial. Ivan Aprahamian receives national public grant level 2 by the National Council for Scientific and Technological Development (Ministry of Science, Technology, Innovation and Communications, Brazil). Mikel Izquierdo receives grant by ISCIII and Fondos FEDER (PI17/01814).

\section{Availability of data and materials}

The datasets generated during and/or analyzed during the present study will be available from the corresponding author on reasonable request.

\section{Ethics approval and consent to participate}

This study received ethical approval from the Research Ethics Committee of the Jundiaí Medical School. All participants will sign informed consent forms.

\section{Consent for publication}

The authors will obtain consent from the participants to publish individual patient data.

\section{Competing interests}

The authors declare no competing interests. Ivan Aprahamian is an Associate Editor for BMC Geriatrics.

\section{Author details}

${ }^{1}$ Group of Investigation on Multimorbidity and Mental Health in Aging (GIMMA), Division of Geriatrics, Department of Internal Medicine, Faculty of Medicine of Jundiaí, 250 Francisco Telles st, Jundiaí 13202-550, Brazil.

${ }^{2}$ Department of Psychiatry, University Medical Center Groningen, University of Groningen, Groningen, The Netherlands. ${ }^{3}$ Geriatric Unit, Fondazione IRCCS Ca' Granda Ospedale Maggiore Policlinico, University of Milan, Milan, Italy. ${ }^{4}$ Division of Geriatrics, St louis University Medical School, St Louis, MO, USA. ${ }^{5}$ Navarrabiomed, Complejo Hospitalario de Navarra (CHN)-Universidad Pública de Navarra (UPNA), IdiSNA, Pamplona, Spain. ${ }^{6} \mathrm{CIBER}$ of Frailty and Healthy Aging (CIBERFES), Instituto de Salud Carlos III, Madrid, Spain. ${ }^{7}$ Grupo GICAEDS, Programa de Cultura Física, Deporte y Recreación, Universidad Santo Tomás, 110311 Bogotá, Colombia.

Received: 10 December 2020 Accepted: 14 January 2021

Published online: 29 January 2021

\section{References}

1. Dent E, Morley JE, Cruz-Jentoft AJ, Woodhouse L, Rodríguez-Mañas L, Fried LP, et al. Physical frailty: ICFSR international clinical practice guidelines for identification and management. J Nutr Health Aging. 2019;23(9):771-87.

2. Fried LP, Tangen CM, Walston J. Newman a B, Hirsch C, Gottdiener J, et al. frailty in older adults: evidence for a phenotype. J Gerontol A Biol Sci Med Sci. 2001;56(3):M146-56

3. Collard RM, Boter H, Schoevers RA, Oude Voshaar RC. Prevalence of frailty in community-dwelling older persons: a systematic review. Vol. 60. J Am Geriatr Soc. 2012;60(8):1487-92.

4. Siriwardhana DD, Hardoon S, Rait G, Weerasinghe MC, Walters KR Prevalence of frailty and prefrailty among community-dwelling older adults in low-income and middle-income countries: a systematic review and metaanalysis. Vol. 8. BMJ Open. 2018;8(3):1-17.

5. Gill TM, Gahbauer EA, Han L, Allore HG. Trajectories of disability in the last year of life. N Engl J Med. 2010;362(13):1173-80.

6. Clegg A, Young J, lliffe S, Rikkert MO, Rockwood K. Frailty in elderly people. Lancet. 2013;381(9868):752-62.

7. Morley JE, Vellas B, van Kan GA, Anker SD, Bauer JM, Bernabei R, et al. Frailty consensus: a call to action. J Am Med Dir Assoc. 2013;14(6):392-7.

8. Li H, Manwani B, Leng SX. Frailty, inflammation, and immunity. Aging Dis. 2011;2(6):466-73.

9. Soysal P, Stubbs B, Lucato P, Luchini C, Solmi M, Peluso R, et al. Inflammation and frailty in the elderly: a systematic review and metaanalysis. Ageing Res Rev. 2016;31:1-8. 
10. Ogawa K, Sanada K, MacHida S, Okutsu M, Suzuki K. Resistance exercise training-induced muscle hypertrophy was associated with reduction of inflammatory markers in elderly women. Mediat Inflamm. 2010;60:1-7.

11. Sardeli AV, Tomeleri CM, Cyrino ES, Fernhall B, Cavaglieri CR, Chacon-Mikahil MPT. Effect of resistance training on inflammatory markers of older adults: a meta-analysis. Exp Gerontol. 2018;52(2):188-96.

12. Haider S, Grabovac I, Winzer E, Kapan A, Schindler KE, Lackinger C, et al. Change in inflammatory parameters in prefrail and frail persons obtaining physical training and nutritional support provided by lay volunteers: a randomized controlled trial. PLoS One. 2017;12(10):e0185879.

13. Bruunsgaard $H$, Bjerregaard $E$, Schroll M, Pedersen BK. Muscle strength after resistance training is inversely correlated with baseline levels of soluble tumor necrosis factor receptors in the oldest old. J Am Geriatr Soc. 2004; 52(2):237-41.

14. McMahon G, Morse Cl, Winwood K, Burden A, Onambélé GL. Circulating tumor necrosis factor alpha may modulate the short-term detraining induced muscle mass loss following prolonged resistance training. Front Physiol. 2019;10:527.

15. Izquierdo M, Rodriguez-Mañas $L$, Sinclair AJ, Group VI. What is new in exercise regimes for frail older people — how does the Erasmus Vivifrail project take us forward? J Nutr Heal Aging. 2016;20(7):736-7.

16. Izquierdo M, Casas-Herrero A, Zambom-Ferraresi F. Multicomponent physical exercise program VIVIFRAIL; 2017.

17. Martínez-Velilla N, Casas-Herrero A, Zambom-Ferraresi F, Sáez De Asteasu ML, Lucia A, Galbete A, et al. Effect of exercise intervention on functional decline in very elderly patients during acute hospitalization: a randomized clinical trial. JAMA Intern Med. 2019;179(1):28-36.

18. Sáez de Asteasu ML, Martínez-Velilla N, Zambom-Ferraresi F, CasasHerrero Á, Cadore EL, Galbete A, et al. Assessing the impact of physical exercise on cognitive function in older medical patients during acute hospitalization: Secondary analysis of a randomized trial. PLoS Med. 2019;16(7):e1002852

19. Izquierdo M, Casas-Herrero A, Zambom-Ferraresi F, Martínez-Velilla N, Alonso-Bouzón CR-ML. Multicomponent physical exercise program VIVIFRAI L; 2019 .

20. Chan A-W, Tetzlaff JM, Gotzsche PC, Altman DG, Mann H, Berlin JA, et al. SPIRIT 2013 explanation and elaboration: guidance for protocols of clinical trials. BMJ. 2013:346:e7586.

21. Moher D, Schulz KF, Altman DG. The CONSORT statement: revised recommendations for improving the quality of reports of parallel-group randomised trials. Lancet. 2001;357(9263):1191-4.

22. Neri AL, Yassuda MS, LF de A, M do C E, Cabral BE, MEC de S, et al. Metodologia e perfil sociodemográfico, cognitivo e de fragilidade de idosos comunitários de sete cidades brasileiras: Estudo FIBRA. Cad Saude Publica. 2013;29(4):778-92.

23. Guralnik JM, Ferrucci L, Pieper CF, Leveille SG, Markides KS, Ostir GV, et al. Lower extremity function and subsequent disability: consistency across studies, predictive models, and value of gait speed alone compared with the short physical performance battery. J Gerontol Ser A Biol Sci Med Sci. 2000;55(4):M221-31.

24. Guralnik JM, Simonsick EM, Ferrucci L, Glynn RJ, Berkman LF, Blazer DG, et al. A short physical performance battery assessing lower extremity function: association with self-reported disability and prediction of mortality and nursing home admission. J Gerontol. 1994;49(2):M85-94.

25. Muir-Hunter SW, Wittwer JE. Dual-task testing to predict falls in communitydwelling older adults: a systematic review. Physiotherapy. 2016;102(1): 29-40.

26. Castelo MS, Coelho-Filho JM, Carvalho AF, Lima JWO, Noleto JCS, Ribeiro $K G$, et al. Validity of the Brazilian version of the geriatric depression scale (GDS) among primary care patients. Int Psychogeriatrics. 2010;22(1):109-13.

27. Barbosa-Silva TG, Menezes AMB, Bielemann RM, Malmstrom TK, Gonzalez MC. Enhancing SARC-F: Improving Sarcopenia Screening in the Clinical Practice. J Am Med Dir Assoc. 2016;17(12):1136-41.

28. Dent E, Morley JE, Cruz-Jentoft AJ, Arai H, Kritchevsky SB, Guralnik J, et al. International clinical practice guidelines for sarcopenia (ICFSR): screening, diagnosis and management. J Nutr Health Aging. 2018;22(10):1148-61.

29. Hecksteden A, Faude O, Meyer T, Donath L. How to construct, conduct and analyze an exercise training study? Front Physiol. 2018;9:1007.

30. Izquierdo M, Rodriguez-Mañas L, Sinclair AJ. What is new in exercise regimes for frail older people - how does the Erasmus Vivifrail project take us forward? J Nutr Health Aging. 2016;20(7):736-7.
31. Bautmans I, Njemini R, Vasseur S, Chabert H, Moens L, Demanet C, et al. Biochemical changes in response to intensive resistance exercise training in the elderly. Gerontology. 2005;51(4):253-65.

32. Michaud M, Balardy L, Moulis G, Gaudin C, Peyrot C, Vellas B, et al. Proinflammatory cytokines, aging, and age-related diseases. J Am Med Dir Assoc. 2013;14(12):877-82.

33. Cesari $M$. The frailty phenotype and sarcopenia: similar but not the same. Aging Med. 2019;2(2):97-8.

34. Travers J, Romero-Ortuno R, Bailey J, Cooney MT. Delaying and reversing frailty: a systematic review of primary care interventions. Br J Gen Pract. 2019;69(678):E61-9.

35. Giunta S. Exploring the complex relations between inflammation and aging (inflamm-aging): anti-inflamm-aging remodelling of inflamm- aging, from robustness to frailty. Inflamm Res. 2008;57(12):558-63.

36. García-Hermoso A, Ramirez-Vélez R, Sáez de Asteasu ML, Martínez-Velilla N, Zambom-Ferraresi F, Valenzuela PL, et al. Safety and effectiveness of longterm exercise interventions in older adults: a systematic review and metaanalysis of randomized controlled trials. Sports Med. 2020;50(6):1095-106.

37. Izquierdo M, Morley JE, Lucia A. Exercise in people over 85. BMJ. 2020;368: m402.

\section{Publisher's Note}

Springer Nature remains neutral with regard to jurisdictional claims in published maps and institutional affiliations.
Ready to submit your research? Choose BMC and benefit from:

- fast, convenient online submission

- thorough peer review by experienced researchers in your field

- rapid publication on acceptance

- support for research data, including large and complex data types

- gold Open Access which fosters wider collaboration and increased citations

- maximum visibility for your research: over $100 \mathrm{M}$ website views per year

At BMC, research is always in progress.

Learn more biomedcentral.com/submissions 